\title{
Fabrication of Relaxer-Based Piezoelectric Energy Harvesters Using a Sacrificial Poly-Si Seeding Layer
}

\author{
E.M.A. FUENTES-FERNANDEZ, ${ }^{1}$ A.M. SALOMON-PRECIADO,${ }^{1}$ B.E. \\ GNADE,${ }^{1}$ M.A. QUEVEDO-LOPEZ ${ }^{1}$ P. SHAH, ${ }^{2}$ and H.N. ALSHAREEF ${ }^{3,4}$ \\ 1.-University of Texas at Dallas, 800 W. Campbell Rd, Richardson, TX 75080, USA. 2.-Texas \\ Micro Power Inc., 7920 Beltline Rd, Suite 1005, Dallas, TX 75254, USA. 3.-Materials Science \& \\ Engineering, King Abdullah University of Science \& Technology (KAUST), Thuwal 23955-6900, \\ Saudi Arabia. 4.-e-mail: husam.alshareef@kaust.edu.sa
}

The effect of a polycrystalline silicon (poly-Si) seeding layer on the properties of relaxor $\mathrm{Pb}\left(\mathrm{Zr}_{0.53}, \mathrm{Ti}_{0.47}\right) \mathrm{O}_{3}-\mathrm{Pb}\left(\mathrm{Zn}_{1 / 3}, \mathrm{Nb}_{2 / 3}\right) \mathrm{O}_{3}$ ( $\left.\mathrm{PZT}-\mathrm{PZN}\right)$ thin films and energy-harvesting cantilevers was studied. We deposited thin films of the relaxor on two substrates, with and without a poly-Si seeding layer. The seeding layer, which also served as a sacrificial layer to facilitate cantilever release, was found to improve morphology, phase purity, crystal orientation, and electrical properties. We attributed these results to reduction of the number of nucleation sites and, therefore, to an increase in relaxor film grain size. The areal power density of the wet-based released harvester was measured. The power density output of the energy harvester with this relaxor composition and the poly-Si seeding layer was $325 \mu \mathrm{W} / \mathrm{cm}^{2}$.

Key words: Energy harvesting, piezoelectric, relaxor, perovskite, cantilever, integration

\section{INTRODUCTION}

The search for ways of harvest energy has recently been accelerating. ${ }^{1-3}$ One way of harvesting energy is by use of vibrations, an abundant source of energy ${ }^{4,5}$ because kinetic energy is typically present in vibrations, random displacements, or forces. ${ }^{6}$ The amount of energy generated by vibrations depends fundamentally on the quantity and form of the kinetic energy available and on the efficiency of the energy harvester. To harvest vibrations, it is necessary to convert mechanical energy into electrical energy by use of an electromechanical transducer. There are five types of electromechanical transducer: electromagnetic, ${ }^{7,8}$ electrostatic, ${ }^{8-10}$ magnetostrictive, ${ }^{11}$ triboelectric, ${ }^{12}$ and piezoelectric. ${ }^{5,8,10,13-15}$ The ease of integration of piezoelectric transducers into microscale devices make them a good option for energy harvesting applications in silicon-compatible technology. ${ }^{10}$ Identification of materials with piezoelectric properties has therefore become of great

(Received January 14, 2014; accepted June 30, 2014; published online August 7, 2014) interest. ${ }^{13,14,16}$ Evaluation of the piezoelectric properties of thin films for integrated energy-harvesting devices has primarily focused on $\mathrm{Pb}(\mathrm{Zr}, \mathrm{Ti}) \mathrm{O}_{3}$, or PZT. ${ }^{2,17}$ Recently, bulk relaxor ferroelectrics have also been studied for energy-harvesting applications; these perform substantially better than conventional PZT. ${ }^{10,18-20}$ However, relaxor thin-films for integrated energy-harvesting applications have not been a topic of much attention.

In the development of piezoelectric energy harvesters, several types of structural geometry have been proposed, with the purpose of power optimization. These include cantilevers, cantilever bimorphs, serpentine structures, double-beam sandwich structures, and tethered structures. ${ }^{21-23}$ The single cantilever configuration is, however, the most studied geometry because it has the optimum coupling characteristics in the $3-1$ bending mode. ${ }^{10,24}$ Two main variants of the cantilever configuration, $\mathrm{d}_{33}$ and $\mathrm{d}_{31}$, depending on the direction of stress relative to the electric field, have been described. ${ }^{10}$ $\mathrm{d}_{33}$ cantilever geometry is, typically, preferred to the $d_{31}$ configuration because the $d_{33}$ piezoelectric constant is approximately twice as large as that of 
$\mathrm{d}_{31}$, which, when combined with larger spacing between the interdigitated electrode fingers relative to the piezoelectric film thickness, enhances piezoelectric power generation. ${ }^{25}$ These cantilevers are typically fabricated by use of the expensive dry-etch process (with $\mathrm{XeF}_{2}$ ). ${ }^{25}$ Here, we used a novel wetetch process that used a sacrificial poly-Si layer to enable release of the cantilever. We found that this sacrificial layer also acted as a seeding layer enabling reduction of the number of nucleation sites. The $d_{33}$ integrated cantilevers were fabricated by use of $\mathrm{Pb}\left(\mathrm{Zr}_{0.53}, \mathrm{Ti}_{0.47}\right) \mathrm{O}_{3}-\mathrm{Pb}\left(\mathrm{Zn}_{1 / 3}, \mathrm{Nb}_{2 / 3}\right) \mathrm{O}_{3}$ (PZT-PZN) relaxor thin-films as the active material. We found that the relaxor ferroelectric phase purity, crystal orientation, morphology, and electrical properties were improved by introduction of the poly-Si sacrificial layer. ${ }^{17}$

\section{EXPERIMENTAL}

The sol-gel solution process used in this work has been described elsewhere. ${ }^{15,26}$ Briefly, the starting B-site alkoxide precursors, zirconium(IV) butoxide, titanium(IV) isopropoxide, and niobium(V) ethoxide, were reacted in acetic acid (95\%), as chelating agent, and methanol, as solvent. Lead(IV) acetate and zinc acetate dihydrate were added, and the solution was then heated to $85^{\circ} \mathrm{C}$ to dissolve the acetates. The concentration of the final PZT-PZN solution was $0.4 \mathrm{M}$. To prepare the $\mathrm{PbTiO}_{3}$ (PT) film, the solution was prepared similarly, but with titanium(IV) isopropoxide and lead(IV) acetate.

The $\quad 0.9 \mathrm{~Pb}\left(\mathrm{Zr}_{0.53}, \mathrm{Ti}_{0.47}\right) \mathrm{O}_{3}-0.1 \mathrm{~Pb}\left(\mathrm{Zn}_{1 / 3}, \mathrm{Nb}_{2 / 3}\right) \mathrm{O}_{3}$ films were deposited by spin-coating then crystalized at $675^{\circ} \mathrm{C}$ for 30 min in air. ${ }^{13}$ The PZT-PZN thin films were deposited on two stacks that differed by inclusion of a $3 \mu \mathrm{m}$ thick poly-Si layer on one, as shown in Fig. 1. The stack with the poly-Si layer (Fig. 1b) consisted of $3 \mu \mathrm{m}$ of Poly-Si, $100 \mathrm{~nm}$ of thermal $\mathrm{SiO}_{2}, 500 \mathrm{~nm}$ of $\mathrm{Si}_{3} \mathrm{~N}_{4}$ deposited under tensile stress by use of low-pressure chemical vapor deposition (LPCVD), $500 \mathrm{~nm}$ of $\mathrm{SiO}_{2}$ deposited by plasma-enhanced chemical vapor deposition (PECVD), and $50 \mathrm{~nm}$ of sputtered Ti. The entire stack was then annealed at $1000^{\circ} \mathrm{C}$ for $30 \mathrm{~min}$ in $\mathrm{O}_{2}$ to completely oxidize the $\mathrm{Ti}$ to $\mathrm{TiO}_{2}$. The purpose of the $\mathrm{TiO}_{2}$ buffer layer was to passivate the substrate, reducing reactions between $\mathrm{Pb}$ from the relaxor film and $\mathrm{Si}$ from the underlying $\mathrm{SiO}_{2} . \mathrm{SiO}_{2}$ acts as a passivation layer for the $\mathrm{Si}_{3} \mathrm{~N}_{4}$, which is necessary to increase the mechanical strength of the device. We then deposited $810 \mathrm{~nm}$ of PZT-PZN on the $\mathrm{TiO}_{2}$ layer. Interdigitated electrodes (IDEs) were deposited on top of the PZT-PZN films. The IDEs consisted of $50 \mathrm{~nm}$ of sputtered $\mathrm{RuO}_{2}$, followed by $50 \mathrm{~nm}$ of $\mathrm{Cr}$ and $500 \mathrm{~nm}$ of $\mathrm{Au}$ deposited by use of e-beam evaporation. This was followed by four patterning steps, the first of which was IDE patterning by use of lift-off lithography. The second step was patterning of the encapsulation layer $(100 \mathrm{~nm}$ of PECVD $\mathrm{SiO}_{2}$ ). The third step was bond-pad
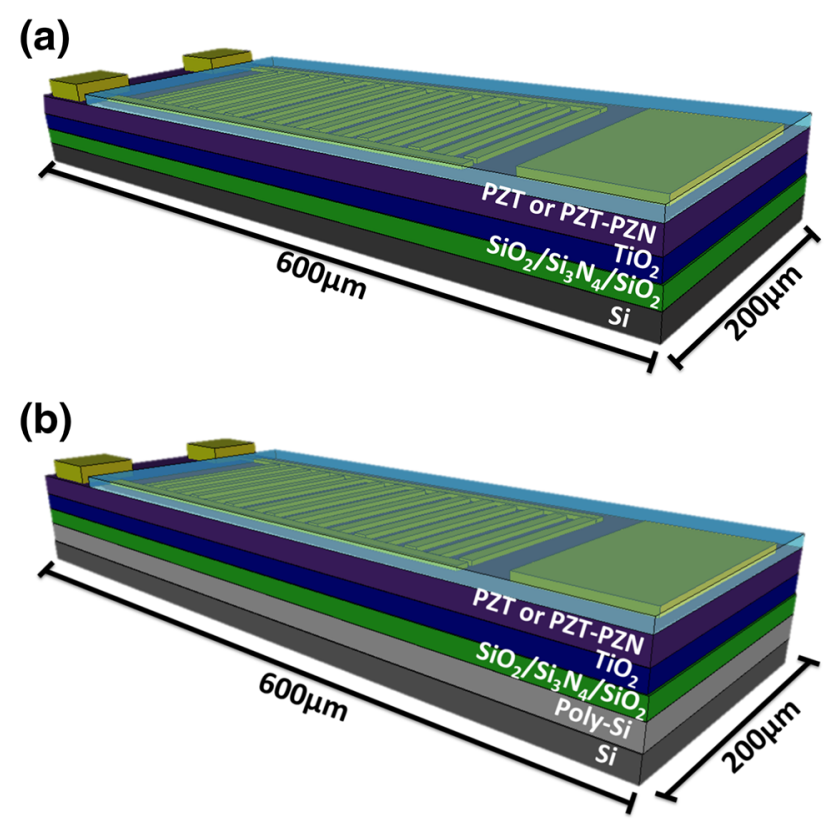

Fig. 1. Schematic diagram of a cross-section of the stacks used for the study: (a) without poly-Si, (b) with poly-Si.

patterning. The fourth step was cantilever patterning. The stack was then etched in $20 \% \mathrm{HF}$ to remove the $\mathrm{PZT}-\mathrm{PZN}, \mathrm{TiO}_{2}$, and $\mathrm{SiO}_{2}$ layers. Next, plasma etching was used to remove the $\mathrm{Si}_{3} \mathrm{~N}_{4} / \mathrm{SiO}_{2}$ layers. Finally the sacrificial poly-Si layer was etched away in $20 \% \mathrm{KOH}$ at $50^{\circ} \mathrm{C}$ to release the cantilever. At $50^{\circ} \mathrm{C}, \mathrm{KOH}$ is very selective for the poly-Si layer. A more-detailed discussion of the fabrication and characterization of the PZT-PZN has been reported elsewhere. ${ }^{27}$ Figure 2 shows a flow diagram of the general process of cantilever fabrication.

The roughness of the film was measured by use of atomic force microscopy (AFM). An image of the microstructure of the film was obtained by use of scanning electron microscopy (SEM), and phase purity and crystal orientation were determined by use of $\mathrm{x}$-ray diffraction (XRD). Capacitance versus voltage $(C-V)$ curves were plotted for the devices by use of a Keithley 4200 semiconductor analyzer and an inductance-capacitance-resistance (LCR) meter (HP 4284). The cantilevers were subsequently packaged and tested by mounting them on a mechanical shaker (Vibration Research Corporation model VR5800). The force generated by the shaker was proportional to the acceleration selected, which was determined by the applied voltage from a highpower amplifier (VR565 linear power amplifier). The acceleration and frequency were monitored with an accelerometer mounted on the piston of the shaker. The amplifier was driven by a $12-\mathrm{V}$ power supply and signals from a frequency generator. The output voltage from the cantilever was monitored by use of a Tektronix digital oscilloscope (TDS 210); an external variable resistance was connected to increase the load resistance. ${ }^{22,24,25}$ 


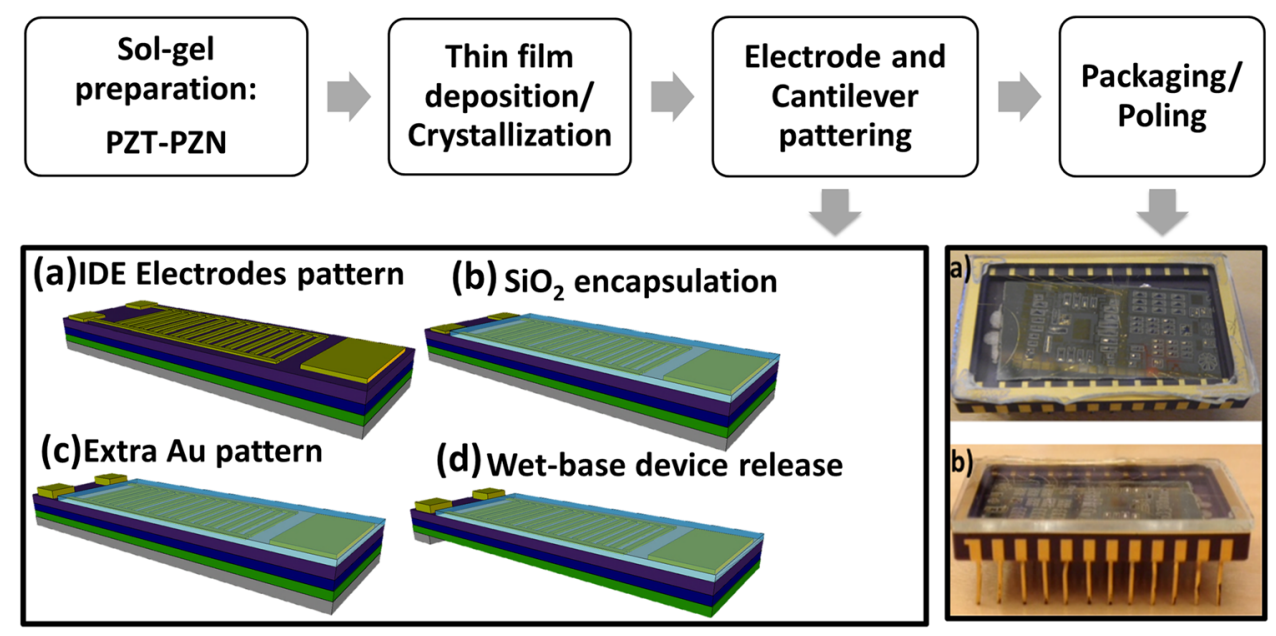

Fig. 2. Flow diagram of cantilever device fabrication.

Table I. AFM average roughness of stacks with and without poly-Si sacrificial layer

\begin{tabular}{|c|c|c|}
\hline & $\begin{array}{c}\text { With poly-Si } \\
\text { (nm) }\end{array}$ & $\begin{array}{c}\text { Without poly-Si } \\
(\mathbf{n m})\end{array}$ \\
\hline Thermal $\mathrm{SiO}_{2}$ & 38.1 & 0.375 \\
\hline $\mathrm{TiO}_{2}$ & 58.8 & 3.8 \\
\hline PZT-PZN & 12 & 1.3 \\
\hline
\end{tabular}

\section{RESULTS AND DISCUSSION}

The surface morphology of the devices was examined at different stages of the cantilever fabrication process. Table I shows the average roughness of each layer in the cantilever stack at different stages in the process. The average roughness $\left(R_{\mathrm{a}}\right)$ of thermal $\mathrm{SiO}_{2}$ growth on stacks with and without poly-Si was measured to be $38.1 \mathrm{~nm}$ and $0.375 \mathrm{~nm}$, respectively. The average surface roughness of the $\mathrm{TiO}_{2}$ deposited on stacks with and without poly-Si was $58.8 \mathrm{~nm}$ and $3.8 \mathrm{~nm}$, respectively. Finally, the last stage measured was after the PZT-PZN deposition on stacks with and without poly-Si; average roughness was $12 \mathrm{~nm}$ and $1.3 \mathrm{~nm}$, respectively. The microstructures of the PZT-PZN thin films in both stacks are shown in Figs. 3a, b. The figure shows that the stack with the poly-Si layer has a denser film (uniform film with no pinholes), with an average grain size of $200 \mathrm{~nm}$, compared with an average grain size of approximately $50 \mathrm{~nm}$ for the PZT-PZN film without the poly-Si seed layer. We attributed the formation of the larger grains to the poly-Si seeding layer, which apparently reduced the number of nucleation sites in the early stages of PZTPZN relaxor thin-film crystallization, which resulted in the formation of fewer but larger grains. $^{25,28}$ It is apparent from Fig. 3a that the PZT-PZN film grown without the poly-Si layer has a second phase, as evidenced by the large number of
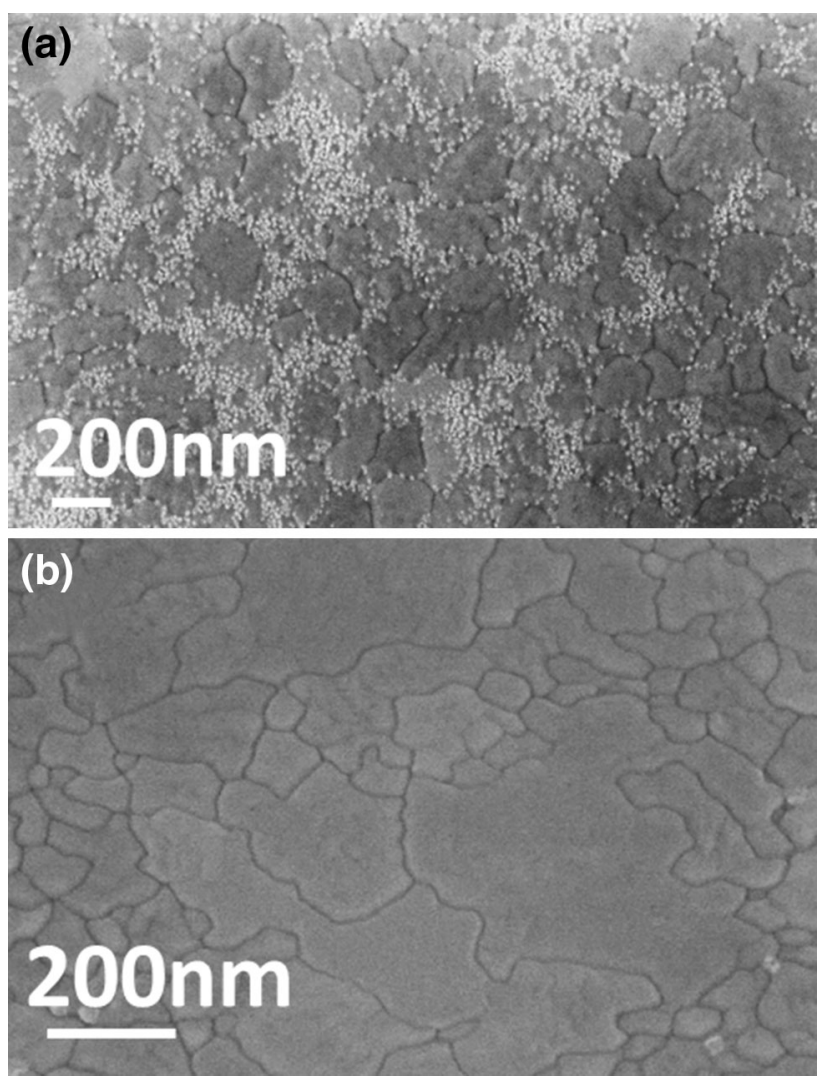

Fig. 3. SE micrographs of the PZT-PZN on stacks (a) without poly$\mathrm{Si}$ and (b) with poly-Si.

bright and small particles that cover the surface. To confirm the presence of the second phase, the XRD pattern was measured for both films; the XRD results are presented in Fig. 4. This figure reveals that the intense poly-Si peak in the film with the poly-Si layer is the major difference between the two films. The perovskite phase is present in both films, with higher intensity in the (110) direction in both 


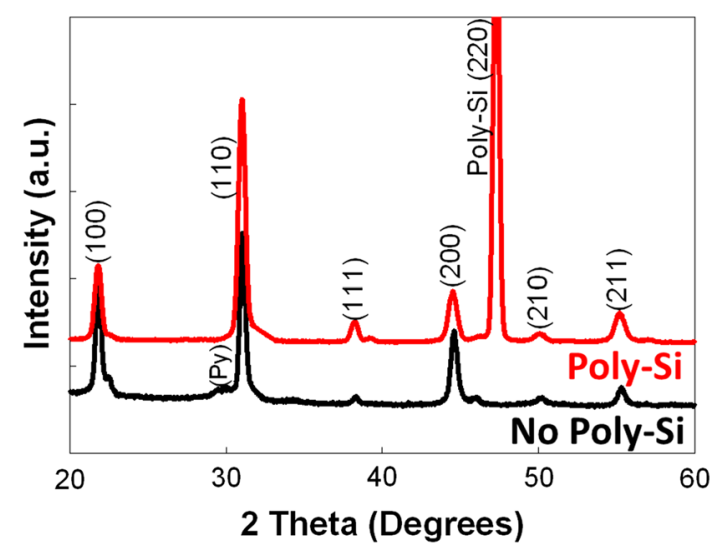

Fig. 4. XRD patterns of the labeled PZT-PZN on stacks without and with poly-Si. The second phase is indicated by "Py". X-ray source: Rigaku Ultima III X-ray diffractometer with $\mathrm{CuK}_{\alpha}(\lambda)=1.54 \AA$, operated at $40 \mathrm{kV}$ and $44 \mathrm{~mA}$.

cases. However, a minor pyrochlore phase $(222)$ is observed at approximately $29^{\circ}$ in the PZT-PZN film deposited on the stack without poly-Si (it is indicated by "Py" in Fig. 4), confirming the presence of the second phase observed in Fig. 3a. It is evident that the poly-Si helps to eliminate the second phase (Fig. 3b).

Interdigitated electrodes (IDEs) were deposited on the relaxor thin films. After the IDE pattering step, capacitance-voltage measurements were obtained for the device structures shown in Fig. 5. The results from the capacitance measurements were used to calculate the dielectric constants of the relaxor thin films. The results are presented in Fig. 6. The $C-V$ curves clearly demonstrate the superior performance of the cantilever stack based on the poly-Si seeding layer (Fig. 6a), for which the peak capacitance was improved by nearly $23 \%$. The dielectric constant (Fig. 6b) was determined by use of the method reported by Dimos et al. ${ }^{29}$ and Henderson ${ }^{30}$. Specifically, the dielectric constant is given by:

$$
\varepsilon_{\mathrm{PZT}-\mathrm{PZN}}=\varepsilon_{s}+\left\{\frac{C-\left[K\left(1+\varepsilon_{\mathrm{s}}\right)\right]}{K\left[1-\exp \left(\frac{-4.6 t_{\mathrm{PZT}-\mathrm{PZN}}}{L}\right)\right]}\right\},
$$

where $\varepsilon_{\text {PZT-PZN }}$ is the permittivity of the PZT-PZN film, $\varepsilon_{\mathrm{S}}$ is the permittivity of the substrate, $t_{\mathrm{PZT}-\mathrm{PZN}}$ is the thickness of the PZT-PZN film, $C$ is a value calculated by use of Eq. $2, C_{\mathrm{m}}$ is the measured capacitance, $D$ is the finger spacing, $F_{\mathrm{L}}$ is the finger length, $N=2 P-1$, where $P$ is the number of finger pairs in the IDE pattern, and $K$ is a geometric constant defined by the center-to-center spacing, $L$, as given in Eq. $3:^{15,29,30}$

$$
\begin{gathered}
C=\frac{C_{m}}{F_{L} * N} \\
K=6.5\left(\frac{D}{L}\right)^{2}+1.08\left(\frac{D}{L}\right)+2.37
\end{gathered}
$$
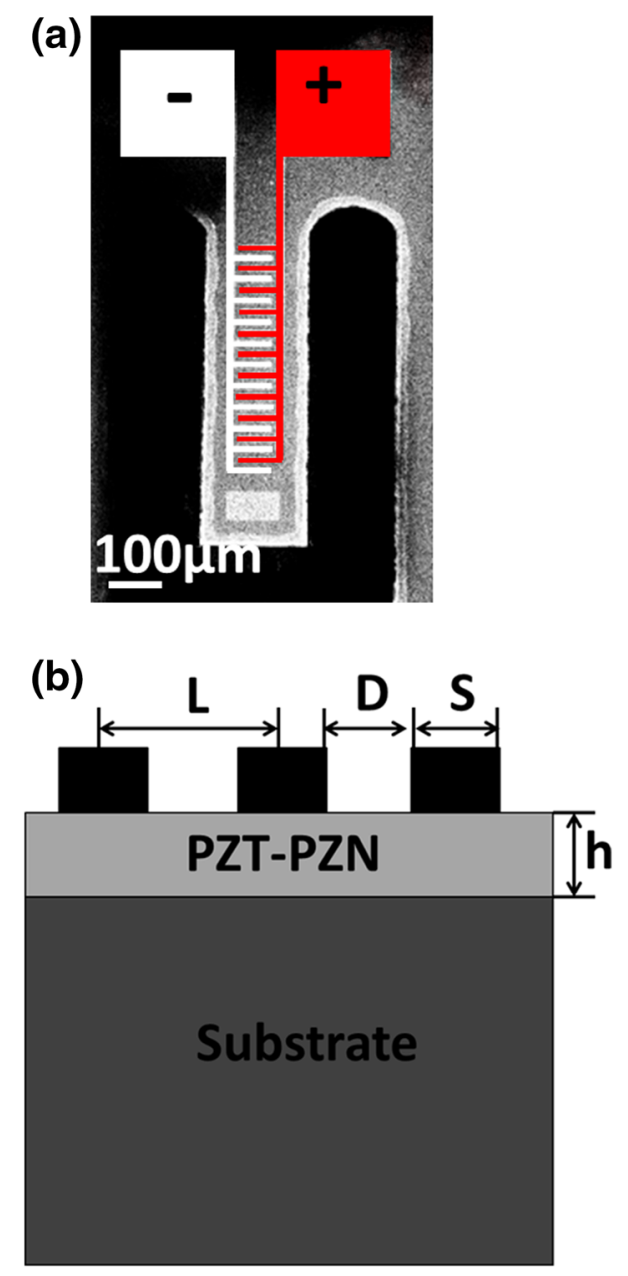

Fig. 5. SE micrograph (a) and schematic diagram of the crosssection (b) of the interdigitated electrode patterns used to test the PZT-PZN films.

The calculated value of the dielectric constant $(3,700)$ is comparable with results reported for similar films. ${ }^{31,32}$

We also measured the polarization of the PZTPZN thin films in both stacks by use of a Radiant Technologies ferroelectric test system. The results are presented in Fig. 7. The maximum polarization measured for the stack with the poly-Si layer was $35 \mu \mathrm{C} / \mathrm{cm}^{2}$, whereas for the stack without the polySi layer the maximum polarization was $25 \mu \mathrm{C} / \mathrm{cm}^{2}$. These values are comparable with those previously reported for PZT-PZN films. ${ }^{33-37}$ The dielectric constant and polarization values for the stack with poly-Si are indicative of $24 \%$ improvement compared with the values obtained for the stack without poly-Si. The improvement in the dielectric constant is attributed to reduction of the number of nucleation sites as a result of the poly-Si.

"Nucleation-controlled" growth requires substantial activation energy for nucleation and then less energy for continued growth. ${ }^{38}$ This method of growth starts from arbitrary defects, for example 
(a)

(b)
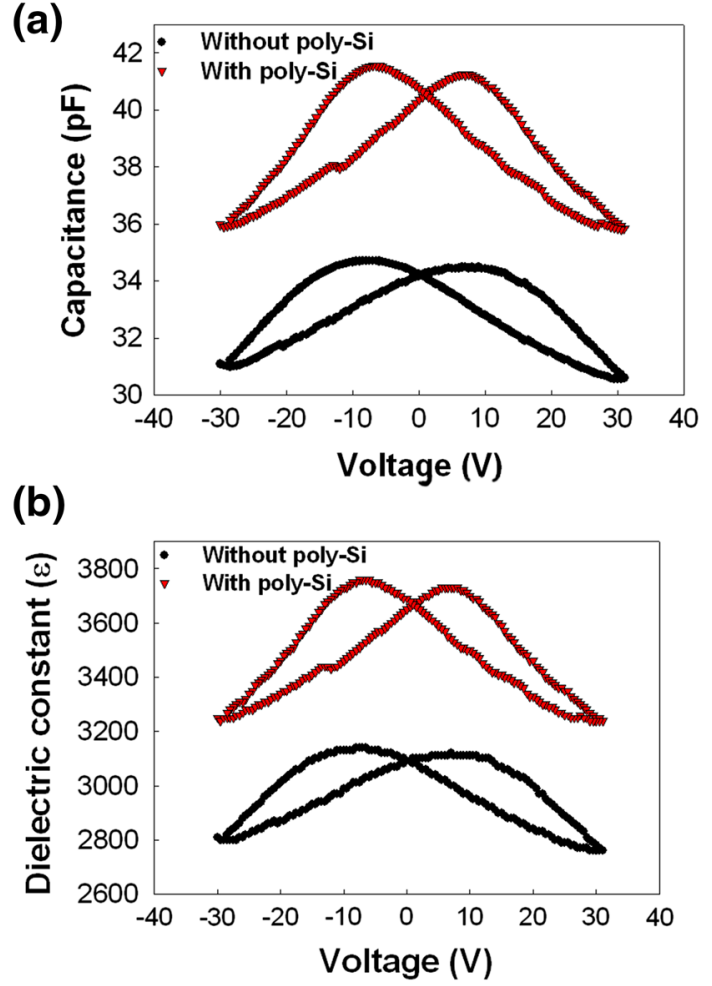

Fig. 6. Plot showing (a) capacitance as a function of voltage $(C-V)$ and (b) the dielectric constant calculated on the basis of $C-V$ measurements of PZT-PZN devices, with and without the poly-Si layer. $C-V$ measurements were obtained at $1 \mathrm{MHz}$.

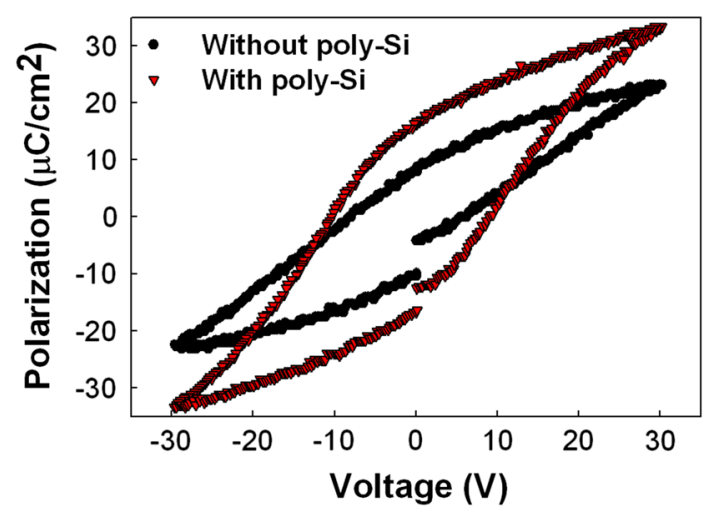

Fig. 7. Polarization curves of PZT-PZN deposited on stacks with and without poly-Si.

grain boundaries in the poly-Si layer. $\mathrm{Pt}$ and $\mathrm{TiO}_{2}$ have been reported to be good nucleation-controlled growth layers. ${ }^{39-41}$ Muralt ${ }^{38}$ described a method for study of nucleation-controlled growth. ${ }^{42}$ For nucleation to occur, an embryonic nucleus must be created by migration of adspecies that become attached to each other. ${ }^{43}$ Most of the embryonic nuclei will decay, and this probability of decay is known as the Zeldovich factor in the nucleation rate. ${ }^{38}$ The most stable nuclei manage to grow quickly, as described in the earliest theories on nucleation by Volmer and
Weber. ${ }^{44}$ Nucleation has been observed to be much more frequent at grain boundaries. If we analyze the films with and without the poly-Si layer, we find that when the poly-Si layer is added to the stack, the subsequent layers are affected, resulting in a film of $\mathrm{TiO}_{2}$ with a grain size five times larger than one grown on a single Si crystal. As a consequence, the PZT-PZN film on top of $\mathrm{TiO}_{2}$ also grows almost four times larger (Fig. 3). As the main nucleation sites are the grain boundaries, reduction of the number of grain boundaries (because of the increase in grain size) reduces the number of nucleation sites from which the relaxor thin film can grow. Films deposited on substrates containing the poly-Si layer therefore have larger grains. These larger grains introduce more domain states within a single grain and result in films that are less susceptible to reduced remnant polarization and that have better piezoelectric response. ${ }^{45}$ Small grains can lead to a limited number of domains, causing lower remnant polarization and suppressed extrinsic contributions to the piezoelectric response. ${ }^{46}$

Other conditions also critically affect the microstructure of the PZT-PZN films. For example, in sol-gel film processing, several factors which might affect nucleation and growth include the presence of excess $\mathrm{Pb}$, the pyrolysis temperature, and the temperature ramp in the thermal annealing. Here, we kept these conditions constant. In addition, the piezoelectric properties of materials, including PZT and the relaxor materials, are strongly affected by composition, thickness, grain size, defect chemistry, and mechanical boundary conditions. ${ }^{47-50}$ These also were maintained constant in this work.

We tested the power output of the wet-based release cantilevers by subjecting them to a cyclical force, by using a standard shaker set-up to probe the functionality of the wet-based fabrication process. The cantilever device was poled at $200 \mathrm{kV} / \mathrm{cm}$ at $200^{\circ} \mathrm{C}$ for $50 \mathrm{~min}$. An acceleration of $10 \mathrm{~g}$ at a frequency of $3.6 \mathrm{kHz}$ was applied to the cantilevers. The cantilever with the poly-Si layer delivered approximately $40 \mathrm{mV}$ in a peak-to-peak open circuit and an output power density (the power output divided by the total device area) of $325 \mu \mathrm{W} / \mathrm{cm}^{2}$, as shown in Fig. $8{ }^{21,25}$ A general vibration test circuit, in which an external load resistance was necessary to perform the measurements, is shown in the inset

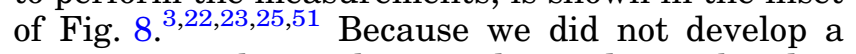
process to release the cantilever device by dryetching, we sent the samples to an external laboratory to release the devices. Although the power output results for the released devices without the poly-Si layer were inconsistent, they were consistently lower than for the devices with the poly-Si layer, because of poor control over the cantilever release process. Thus, in addition to improving device performance, the presence of the poly-Si layer significantly improved the cantilever release process. 


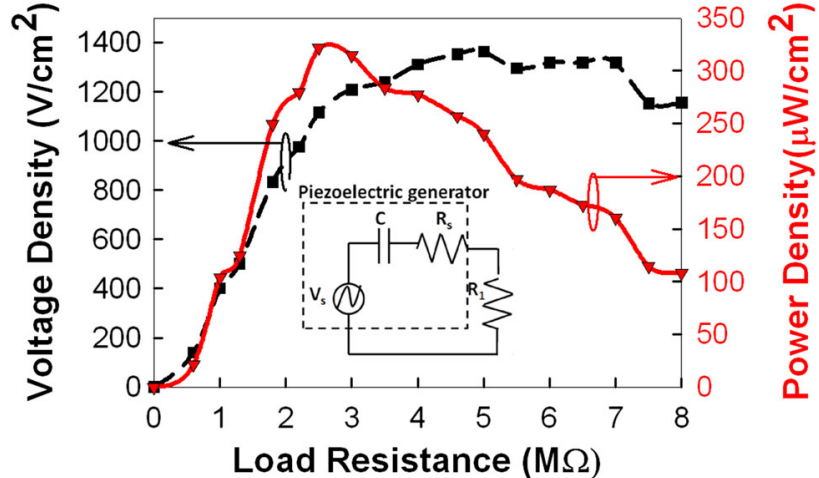

Fig. 8. Resistance match data showing the power and voltage density outputs from a cantilever using poly-Si as a sacrificial layer. Measurements where obtained at $3.6 \mathrm{kHz}$ and $10 \mathrm{~g}$. Voltage and power density mean voltage and power divided by the total device area.

\section{CONCLUSION}

PZT-PZN thin films have been fabricated by solgel processing using a sacrificial poly-Si seeding layer. Significant improvements in microstructure, phase purity, crystal orientation, and electrical properties were observed for films deposited on the stack with the poly-Si seeding layer. A piezoelectric cantilever was successfully fabricated by use of relaxor PZT-PZN thin films and wet-etch processing. The power density of the piezoelectric cantilever was $325 \mu \mathrm{W} / \mathrm{cm}^{2}$.

\section{ACKNOWLEDGEMENTS}

The authors would like to thank the National Science Foundation for the Phase I STTR \#0810391 and Phase IB \#0937831 grants supplemented by the Texas Emerging Technology Fund seed grant (March 2008-Sept 2009). The research reported here was also supported by King Abdullah University of Science and Technology.

\section{REFERENCES}

1. I.R. Henderson, Piezoelectric Ceramics: Principles and Applications (Mackeyville: APC International Ltd., 2002), pp. 23-30.

2. A. Bell, Frontiers of Ferroelectricity (New York, USA: Springer, 2007), p. 13.

3. S. Priya and D.J. Inman, Energy Harvesting Technologies (New York, USA: Springer, 2009), pp. 129-207.

4. S. Priya, C.-T. Chen, D. Fye, and J. Zahnd, Jpn. J. Appl. Phys. 44, L104 (2005).

5. S. Priya, J. Electroceram. 19, 167 (2007).

6. S.P. Beeby, M.J. Tudor, and N.M. White, Meas. Sci. Technol. 17, R175 (2006)

7. X. Bai, Y. Wen, J. Yang, P. Li, J. Qiu, and Y. Zhu, J. Appl. Phys. 111, 07A938 (2012).

8. R. Amirtharajah and A.P. Chandrakasan, IEEE J. SolidState Circuits 33, 687 (1998).

9. P.D. Mitcheson, P. Miao, B.H. Stark, E.M. Yeatman, A.S. Holmes, and T.C. Green, Sens. Actuators A 115, 523 (2004)

10. S. Roundy, P.K. Wright, and J. Rabaey, Comput. Commun. 26, 1131 (2003).

11. W. Lei and F.G. Yuan, Smart Mater. Struct. 17, 045009 (2008).
12. J. Chen, G. Zhu, W. Yang, Q. Jing, P. Bai, Y. Yang, T.-C. Hou, and Z.L. Wang, Adv. Mater. 25, 6094 (2013).

13. E. Fuentes-Fernandez, L. Baldenegro-Perez, M. QuevedoLopez, B. Gnade, A. Hande, P. Shah, and H.N. Alshareef, Solid-State Electron. 63, 89 (2011).

14. L.A. Baldenegro-Perez, W. Debray-Mechtaly, E. FuentesFernandez, M.A. Quevedo-Lopez, H.N. Alshareef, P. Shah, and B.A. Gnade, Mater. Sci. Forum 644, 97 (2010).

15. E. Fuentes-Fernandez, W. Debray-Mechtaly, M.A. QuevedoLopez, B. Gnade, A. Rajasekaran, A. Hande, P. Shah, and H.N. Alshareef, J. Electron. Mater. 40, 85 (2011).

16. A. Hajati and S.-G. Kim, Appl. Phys. Lett. 99, 083105 (2011).

17. S.-H. Kim, Y.-S. Choi, C.-E. Kim, and D.-Y. Yang, Thin Solid Films 325, 72 (1998).

18. S. Priya, H.-W. Kim, and K. Uchino, J. Am. Ceram. Soc. 87, 1907 (2004).

19. V. Raghunathan, C. Schurgers, P. Sung, and M.B. Srivastava, IEEE Signal Process. Mag. 19, 40 (2002).

20. P.D. Mitcheson, T.C. Green, E.M. Yeatman, and A.S Holmes, J. Microelectromech. Syst. 13, 429 (2004).

21. A. Erturk and D.J. Inman, Smart Mater. Struct. 18, 025009 (2009).

22. W.J. Choi, Y. Jeon, J.H. Jeong, R. Sood, and S.G. Kim, J. Electroceram. 17, 543 (2006).

23. W. Yang, J. Chen, G. Zhu, X. Wen, P. Bai, Y. Su, Y. Lin, and Z. Wang, Nano Res. 6, 880 (2013).

24. S. Roundy and P.K. Wright, Smart Mater. Struct. 13, 1131 (2004).

25. Y.B. Jeon, R. Sood, J.h. Jeong, and S.G. Kim, Sens. Actuators A 122, 16 (2005).

26. H.N. Al-Shareef, K.R. Bellur, O. Auciello, X. Chen, and A.I. Kingon, Thin Solid Films 252, 38 (1994).

27. E.M.A. Fuentes-Fernandez, W. Debray-Mechtaly, M.A. Quevedo-Lopez, B. Gnade, E. Leon-Salguero, P. Shah, and H.N. Alshareef, Smart Mater. Res. 2012, 9 (2012).

28. C. Zorman, M. Mehregany, Springer Handbook of Nanotechnology, ed. B. Bhushan, (Berlin: Springer, 2004), pp. 203.

29. D. Dimos, M.V. Raymond, R.W. Schwartz, H.N. Al-Shareef, and C.H. Mueller, J. Electroceram. 1, 145 (1997).

30. G.W. Farnell, I.A. Cermak, P. Silverster, and S.K. Wong, IEEE Trans. Sonics Ultrason. Ind. Eng. Chem. 17, 188 (1970).

31. H. Fan, S.-H. Lee, C.-B. Yoon, G.-T. Park, J.-J. Choi, and H.-E. Kim, J. Eur. Ceram. Soc. 22, 1699 (2002).

32. M.L. Calzada, M. Algueró, A. Santos, M. Stewart, M.G. Cain, and L. Pardo, J. Mater. Res. 24, 526 (2009).

33. T. Haccart, E. Cattan, and D. Remiens, Semicond. Phys. Quantum Electron. Optoelectron. 5, 78 (2002).

34. H. Xiyun, Z. Xia, Z. Xinsen, Q. Pinsun, C. Wenxiu, and D. Aili, J. Phys. Conf. Ser. 152, 012068 (2009).

35. N. Wongdamnern, N. Triamnak, M. Unruan, K. Kanchiang, A. Ngamjarurojana, S. Ananta, Y. Laosiritaworn, and R. Yimnirun, Phys. Lett. A 374, 391 (2010).

36. R. Yimnirun, N. Wongdamnern, N. Triamnak, M. Unruan, A. Ngamjarurojana, S. Ananta, and Y. Laosiritaworn, $J$. Appl. Phys. 103, 086105 (2008).

37. K. Tanaka, T. Kubota, and Y. Sakabe, Sens. Actuators A 96, 179 (2002).

38. P. Muralt, J. Appl. Phys. 100, 051605 (2006)

39. T. Maeder, P. Muralt, L. Sagalowicz, I. Reaney, M. Kohli, A Kholkin, and N. Setter, Appl. Phys. Lett. 68, 776 (1996).

40. P. Muralt, T. Maeder, L. Sagalowicz, S. Hiboux, S. Scalese, D. Naumovic, R.G. Agostino, N. Xanthopoulos, H.J. Mathieu, L. Patthey, and E.L. Bullock, J. Appl. Phys. 83, 3835 (1998).

41. A. Katsuhiro, F. Yukio, N. Ken, and N. Akitoshi, Jpn. J. Appl. Phys. 34, 192 (1995).

42. E. Schulz, Acta Polym. 31, 216 (1980).

43. H. Reiss, J. Chem. Phys. 18, 840 (1950)

44. M. Volmer and A. Weber, Z. Phys. Chem. 119, 277 (1925).

45. B.A. Tuttle, T.J. Garino, J.A. Voight, T.J. Headley, D. Dimos, and M.O. Eatough, Science and Technology of Electroceramic Thin Films (The Netherlands: Kluwer Academic Publishers, 1995), pp. 427-437. 
46. S. Trolier-McKinstry and P. Muralt, J. Electroceram. 12, 7 (2004).

47. N. Kim, (Ph.D. thesis, The Pennsylvania State University, University Park, PA, 1994).

48. T.M. Shaw, S. Trolier-McKinstry, and P.C. McIntyre, Annu. Rev. Mater. Sci. 30, 263 (2000).
49. M.H. Frey and D.A. Payne, Phys. Rev. B 54, 3158 (1996).

50. G. Arlt, D. Hennings, and G. de With, J. Appl. Phys. 58, 1619 (1985).

51. X. Tian-Bing, J.S. Emilie, K. Jin Ho, Z. Lei, Z. Wanlu, and T. Xiudong, J. Xiaoning Smart Mater. Struct. 22, 065015 (2013). 